\title{
Оценка адекватности кинематических зависимостей зернового слоя в вибропитателе
}

\author{
Рындин Александр Алексеевич \\ ФГБОУ ВО «Московский государственный университет \\ пищевых производств» \\ Адрес: 125080, г. Москва, Волоколамское шоссе, д. 11 \\ E-mail: aleksandr-ryndin@rambler.ru \\ Стрелюхина Алла Николаевна \\ ФГБОУ ВО «Московский государственный университет \\ пищевых производств» \\ Адрес: 125080, г. Москва, Волоколамское шоссе, д. 11 \\ E-mail:alstrel@rambler.ru \\ Мачихин Сергей Александрович \\ ФГБОУ ВО «Московский государственный университет \\ пищевых производств» \\ Адрес: 125080, г. Москва, Волоколамское шоссе, д. 11 \\ E-mail:smachexpert@rambler.ru
}

Сорокина Юлия Александровна Государственное бюджетное общеобразовательное учреждение города Москвы «Школа № 1935» Адрес: 109431, г. Москва, ул. Авиаконструктора Миля, д. 18, корп. 2 E-mail: sorokina9101994@yandex.ru

\begin{abstract}
Статья посвящена практической части исследований послойного движения зернового потока по рабочему органу вибрационного сепаратора -питающему лотку, выполненному в виде наклонной поверхности с рифлями переменной высоты, вдоль линии наибольшего ската. Рабочему органу сообщаются поступательные гармонические колебания, направленные перпендикулярно установленным рифлям. Приведены результаты проверки адекватности и траектории зернового слоя, вычисленных с использованием математических, предложенных авторами, и экспериментальных значений. Представлены результаты исследования влияния частоты колебания рабочего органа на траекторию и скорость движения частиц верхнего и нижнего слоев зерновой смеси.
\end{abstract}

Ключевые слова: сепарирующие машины, самосортирование, опорная поверхность, рифли, частота колебаний, амплитуды колебаний

\section{Введение}

В опубликованных ранее статьях (Мачихин, Рындин, Васильев, \& Стрелюхина, 2018; Мачихин, Рындин, Васильев, \& Стрелюхина, 2019) рассмотрен процесс сепарирования зерновой смеси вибрационными сепараторами, у которых в рабочий органа выполнен в виде наклонной поверхности с рифлями переменной высоты, установленными вдоль линии наибольшего ската. Движущийся поток зерновой смеси, представлен в виде двух- слойной модели (Васильев, Мачихин, Стрелюхина, \& Рындин, 2018; Васильев, Мачихин, Стрелюхина, \& Рындин, 2018). Изложены теоретические положения по движению верхнего и нижнего слоев зерновой смеси по поверхности предложенного рабочего органа (Васильев, Рындин, Стрелюхина, Мачихин, 2018).

Авторами проведена экспериментальная проверка выдвинутых теоретических положений (Адлер, Маркова, \& Грановский, 1971; Ермольев \& Коч- 
кин, 2007; Арсеньев и др., 2010; Бочковский, 1940; Бочковский, 1954; Пашинова, 2013; Пелевин, 2011; Абидуев А. А. \& Абидуев Ал. А., 2011; Абидуев, 2010; Буклагина, 2005; Птушкина, 1963; Русанов, 1957; Федоренко, 2016; Фоминых, Пономарева, \& Ездин, 2012).

Данная статья является продолжением статей (Мачихин и др., 2018; Мачихин и др., 2019) и посвящена сопоставлению данных полученных с помощью математического аппарата использованного в предложенных математических моделях и в ходе экспериментальных исследований, выполненных в лабораториях Московского государственного университета пищевых производств.

Исследовали два слоя зернового потока: нижний, движущийся между рифлями и имеющий высоту равную высоте рифлей; и верхний, находящийся над рифлями и движущийся над ними по сложной гармонической траектории (Андреева, 2007; Волков, Васильев, \& Киракосян, 2009; Оспанов \& Овчинников, 2002). Таким образом, было проведено два экскремента.

Целями первого эксперимента являлись исследования траектории и скорости движения частиц верхнего зернового слоя, который расположен над рифлями рабочей поверхности и нижним слоем, состоящим из частиц зерновой смеси, заполняющих пространство между рифлями.

Целями второго эксперимента было исследование изменения скорости перемещения частиц нижнего слоя зерносмеси от частоты колебаний $n$ рабочей поверхности и подтверждение адекватности аналитических зависимостей представленных в статье (Мачихин и др., 2019). Исследования проводили по следующей методике.

\section{Методы исследования}

На Рисунке 1. схематично показано деление потока зерновой смеси на верхний (3) и нижний (2) слои. 1 Обозначена рабочая поверхность, на которой закреплены рифли (4).

\section{Исследование движения частиц верхнего слоя}

При разработке методики экспериментальных исследований по определению траектории и скорости движения частиц верхнего слоя зернового потока был использован международный опыт исследований движения сыпучих материалов, в том

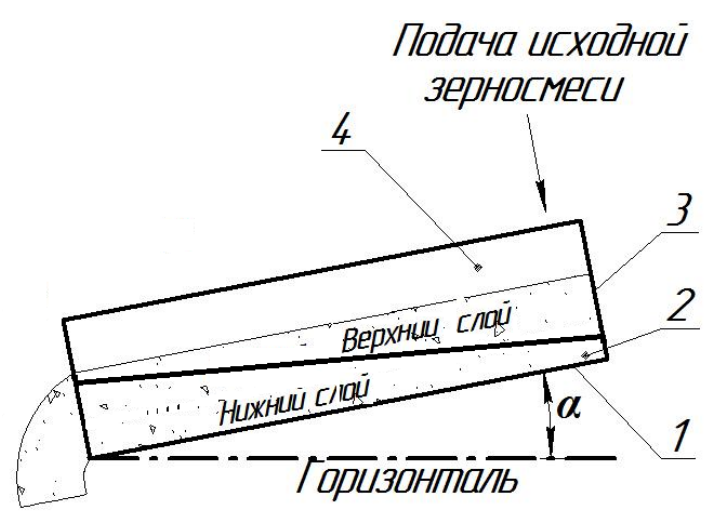

Рисунок 1. Границы верхнего и нижнего слоев потока зерновой смеси

числе проводимых Гортинским В.В. и его коллегами (Васильев и др., 2018).

Известно, что для исследования вибрационного перемещения слоев сыпучего материала применяют различные модельные частицы (Гортинский, Демский, \& Борискин, 1980; Блехман \& Джанелидзе, 1964): крашенные (меченые) зерновки; кружки плотной бумаги (индикаторы), оклеенные зерновками или примесями исследуемой зерновой смеси. Нами использован индикатор, представляющий собой пластмассовый кружок, оклеенный зерновками пшеницы с закрепленным на нем пишущим элементом фломастера.

В процессе эксперимента наклонная поверхность совершала горизонтальные гармонические колебания перпендикулярно линии наибольшего ската; частица совершала движение относительно колеблющейся поверхности под действием двух взаимно перпендикулярных сил: переносной силы инерции и составляющей силы тяжести частицы, направленной вниз вдоль линии наиболь-

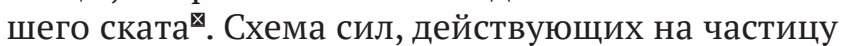
верхнего слоя в относительном движении, находящейся в зерновой смеси, представлена на Рисунке 2.

Исследовали влияние частоты колебаний рабочей поверхности - $n$ на изменения траектории движения частиц верхнего слоя.

Осуществили фиксацию траектории индикатора при его движении с помощью современных средств регистрации. Индикатор располагался в верхнем зерновом слое. Для адекватности условия движения маркера относительно рабочей поверхности условиям движения частиц верхнего слоя относительно нижнего, был исключен контакт индикатора с гладкой поверхностью рабочего орга- 


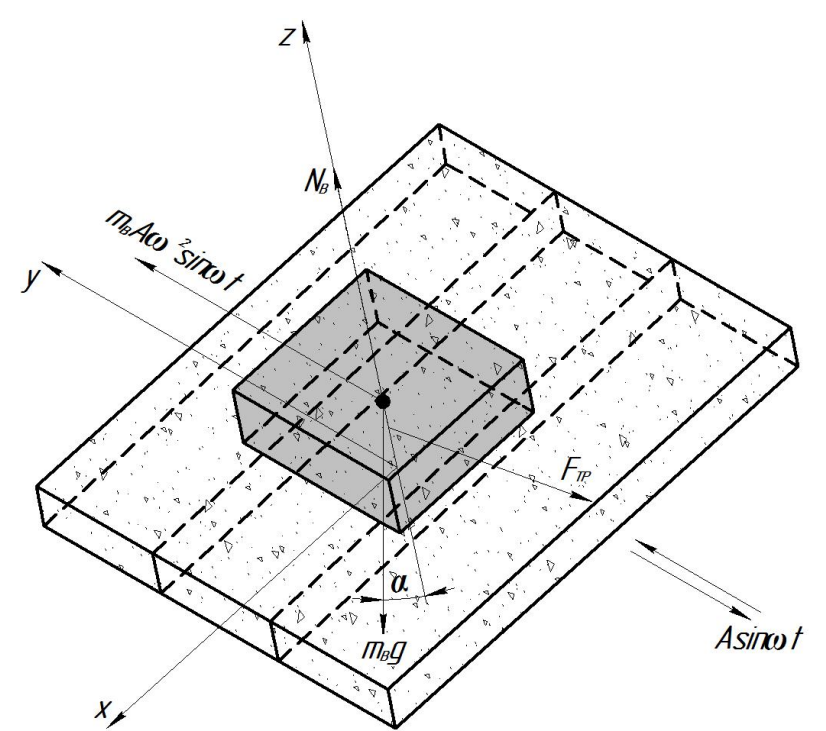

Рисунок 2. Схема сил, действующих на частицу верхнего слоя в относительном движении

на. Такое расположение индикатора обусловлено тем, что на траекторию движения частицы зерновой смеси оказывает влияние коэффициент трения и им нельзя пренебрегать.

Полученная траектория была переведена в двоичную систему координат, в виде множества точек.

Теоретические значения координат частицы в определенные моменты времени вдоль оси были получены по формуле № 30, описывающим полное перемещение частиц (Мачихин и др., 2019).

Проверка адекватности, на основе расчетных данных и полученных экспериментальным путем, проводилась по F-критерию Фишера.

\section{Исследование движения частиц нижнего слоя}

Исследования проводили по следующей методике.

Крашенную (меченную) зерновку помещали в нижний слой зерносмеси между рифлями в определенную фиксированную точку и замеряли время начала опыта. Через промежуток времени $\tau$ фиксировали положение меченной частицы, и замеряли путь S пройденный частицей за время $\tau$. Среднюю скорость частицы между рифлями определяли, как соотношение S (м) к времени $\tau$ (c). Эксперимент проводили при изменении частоты колебаний рабочего органа от 200 до 250 кол/мин. Остальные параметры: амплитуды $A$ горизонтальных колебаний поверхности и угла ее наклона $\alpha$ к горизонтали оставались постоянными.

\section{Результаты и их обсуждение}

На Рисунках 3 - 5 представлены участки траектории частицы верхнего слоя при различных значениях частоты колебаний рабочего органа - $n$ (от 200 до 300 кол/мин), фиксированных значениях амплитуды $A=0,025$ м горизонтальных колебаний поверхности и угла ее наклона $\alpha=3,5^{\circ}$ к горизонтали. Сплошной линией показаны траектории, построенные по результатам расчетов по методике, представленной в (Мачихин и др., 2019), точками отмечены отдельные положения частицы, определенные экспериментально.

При выбранных кинематических и установочных параметрах колебаний рабочей поверхности

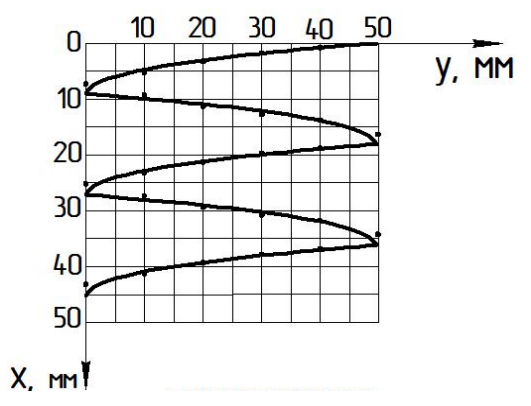

Рисунок 3. Траектория частицы верхнего слоя:экспериментальная; - расчетная. При $A-0,025$ м, $\alpha=3,5^{\circ}, n=200$ кол/мин

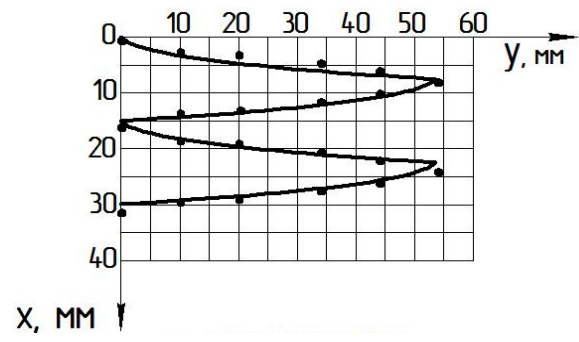

Рисунок 5. Траектория частицы верхнего слоя: экспериментальная; - расчетная. При $A-0,025$ м, $\alpha=3,5^{\circ}, n=300$ кол/мин

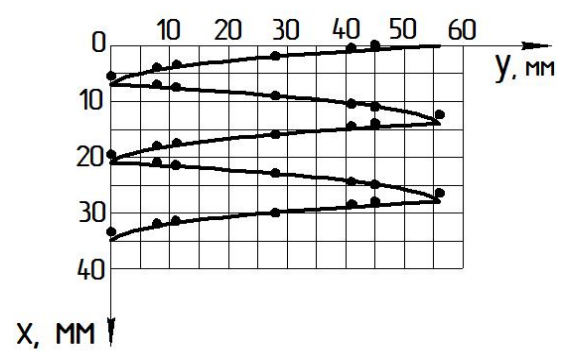

Рисунок 4. Траектория частицы верхнего слоя: экспериментальная; - расчетная. При $A-0,025$ м, $\alpha=3,5^{\circ}, n=250$ кол/мин 
используя предложенную Гортинским В.В. классификацию определяли режим относительного движения частицы (Мачихин и др., 2019). По уравнениям, соответствующим данному режиму, определяли значения фазовых углов начала и окончания относительного скольжения частицы на каждом этапе ее движения. Заметим, что направление скольжения частицы отличаются по оси у. На первом этапе скольжения частица движется в положительном направлении, как вдоль оси $y$, так и вдоль оси $x$. На втором этапе скольжения частица совершает движение в отрицательном направлении оси у и в положительном направлении оси $x$. Рассчитывали координаты частицы в переносной системе координат на каждом этапе ее скольжения с шагом изменения фазового угла колебаний рабочей поверхности, равным 0,1 радиан.

Из анализа полученных результатов сделаны следующие выводы:

- частица совершает колебательное движение относительно прямой, параллельной линии наибольшего ската поверхности с одновременным движением вдоль линии наибольшего ската;

- с увеличением частоты колебаний $n$ рабочей поверхности в диапазоне исследованных значений частоты (от 200 до 300 об/мин) наблюдается незначительный рост амплитуды колебаний частицы;
- при увеличении частоты колебаний поверхности от 200 об/мин до 300 об/мин амплитуда колебаний частицы увеличивается с 0,025 м до 0,028 м;

- с увеличением частоты колебаний поверхности в том же диапазоне перемещение частицы по оси $x$ уменьшается с 18 мм до 14 мм за период колебаний рабочей поверхности;

- движение частицы верхнего слоя можно рассматривать как сложное, состоящее из движений в двух взаимно перпендикулярных направлениях: «быстрое» колебательное движение относительно прямой параллельной линии наибольшего ската и «медленное» эволюционное движение вдоль линии наибольшего ската поверхности.

Математическая модель для построения траектории частицы верхнего слоя зерносмеси приведена (Мачихин и др., 2018).

Проверка адекватности, на основе расчетных данных и полученных экспериментальным путем, проведенная по F-критерию Фишера (Таблица 1), показала, что предложенная динамическая модель адекватно описывает реальный процесс вибрационного перемещения верхнего слоя зерносмеси относительно наклонной рабочей поверхности, совершающей горизонтальные гармонические колебания в направлении, перпендикулярном линии наибольшего ската поверхности.

Таблица 1

Фрагмент анализ совокупности выборок по отсортированному аргументу $Y$

\begin{tabular}{ccccccccccccc}
\hline № & $\mathbf{Y ~ р а с ч ~}$ & $\mathbf{X}$ расч & $\mathbf{Y ~ э к с п е р ~}$ & $\mathbf{X}$ экспер & $\boldsymbol{\Delta} \mathbf{X}$ & № & $\mathbf{Y}$ расч & $\mathbf{X}$ расч & Y экспер & $\mathbf{X}$ экспер & $\Delta \mathbf{X}$ \\
\hline 1 & 0,00 & 8,00 & 0,00 & 7,50 & 0,50 & 19 & 28,00 & 9,00 & 28,00 & 9,00 & 0,00 \\
2 & 0,00 & 0,00 & 0,00 & 0,00 & 0,00 & 20 & 30,00 & 2,00 & 30,00 & 1,90 & 0,10 \\
3 & 0,00 & 15,00 & 0,00 & 15,50 & $-0,50$ & 21 & 30,00 & 12,00 & 30,00 & 12,50 & $-0,50$ \\
4 & 0,00 & 6,00 & 0,00 & 5,50 & 0,50 & 22 & 34,00 & 6,00 & 34,00 & 5,00 & 1,00 \\
5 & 7,50 & 4,00 & 7,50 & 3,50 & 0,50 & 23 & 34,00 & 12,50 & 34,00 & 12,00 & 0,50 \\
6 & 7,50 & 7,50 & 7,50 & 7,00 & 0,50 & 24 & 40,00 & 1,00 & 40,00 & 1,00 & 0,00 \\
\hline
\end{tabular}

На Рисунке 6, для наглядности представлены гистограммы статистических связей всех пар данных массивов X на Ү визуально демонстрирующие их совпадение, что подтверждает адекватность разработанной модели движения верхнего зернового слоя реальному процессу.

Расчетные данные по скорости перемещения частиц нижнего зернового слоя были получены ниже описанной формуле взятой из математической модели движения нижнего зернового слоя (Мачихин и др., 2019).

$\mathrm{V}_{\mathrm{CP}}=\frac{x_{1+}}{\pi} * A \omega \operatorname{tg} \rho_{2}=\frac{x_{2+}}{\pi} * \operatorname{A\omega tg} \rho_{2}$

На Рисунке 7 представлены результаты теоретических и экспериментальных определений средней скорости движения частицы нижнего слоя в 


\section{Статистические связи массивов $\mathrm{Y}$ на $\mathrm{X}$}

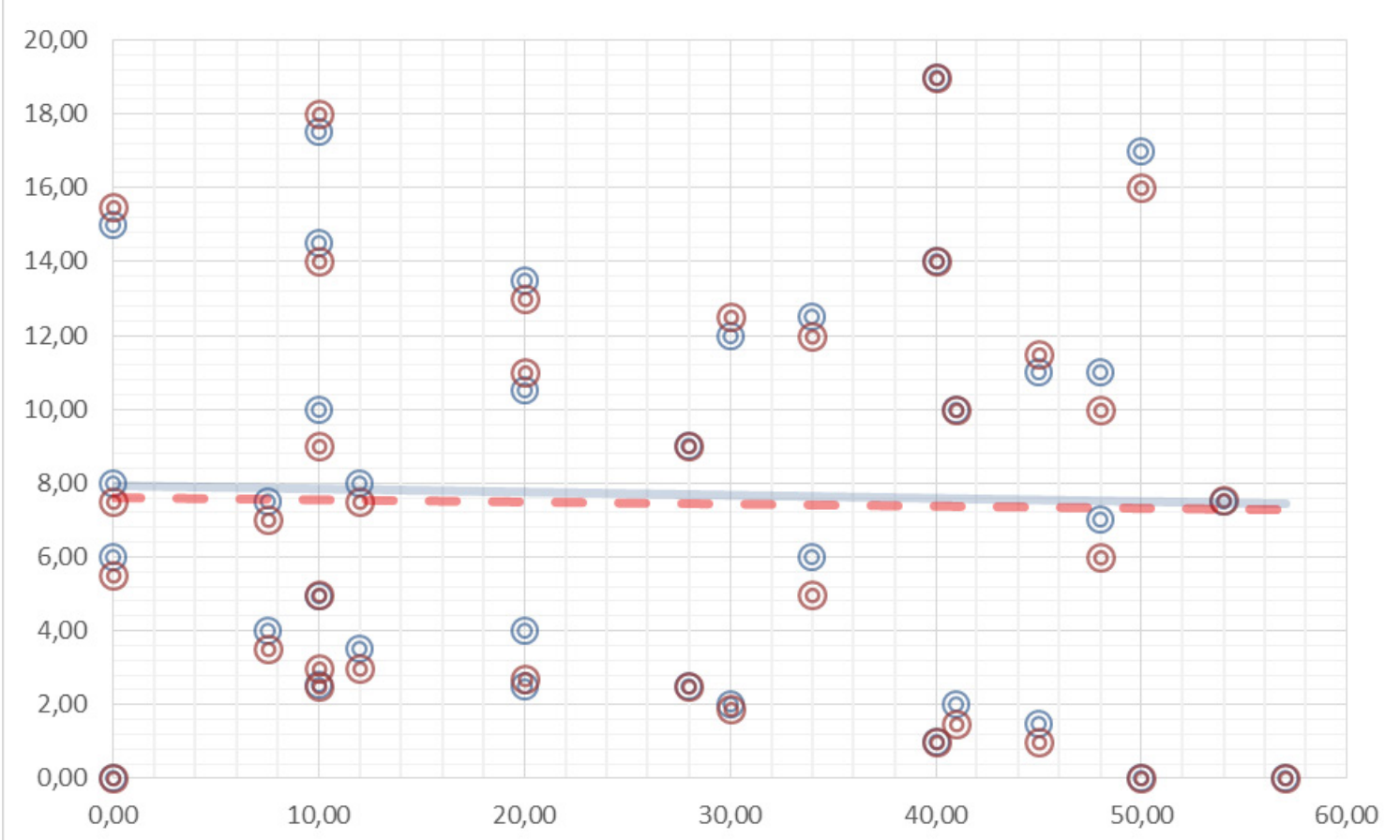

Рисунок 6. Гистограммы пар данных (ось аргумента Y - горизонтально)

зависимости от частоты колебаний рифленой рабочей поверхности. Анализ результатов показал, что изменения $n$ от 200 до 250 кол/мин приводит к увеличению средней скорости нижнего слоя в 1,7 раза.

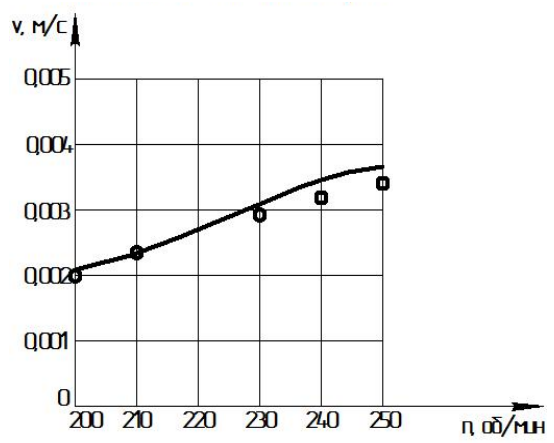

Рисунок 7. Скорость движения частицы нижнего слоя: - экспериментальная; - расчетная. При $A-$ $0,025 \mathrm{M}, \alpha=7,1^{\circ}$.

\section{Были определены величины погрешности}

Сопоставление экспериментальных и расчетных данных, как и в случае исследования верхнего зернового слоя, проведено по F- критерию Фишера. Полученный результат позволяет утверждать, что предложенная математическая модель адекватно описывает реальный процесс перемещения частицы нижнего слоя между рифлями.

\section{Выводы}

Выполненные экспериментальные исследования изменений траектории движения частиц верхнего и нижнего слоев зерновой смеси, и сопоставление данных о траекториях и скорости перемещения частиц, полученных расчетным и лабораторным образом, позволяет говорить об адекватности математических моделей движения зерновой смеси (Мачихин и др., 2019; Мачихин и др., 2018).

Таким образом, можно говорить о возможности использования описанных выше моделей при проектировании вибрационных узлов и агрегатов зерноочистительных машин.

\section{Литература}

Абидуев, А. А. (2010). Совершенствование процесса очистки семенного зерна. Улан-Удэ: Изд-во ФГОУ ВПО БГСХА им. В. Р. Филиппова.

Абидуев, А. А., \& Абидуев А. А. (2011). Обоснование технологии очистки семян пшеницы. Вестник ВСГТУ, 4, 86-90.

Адлер, Ю. П., Маркова, Е. В., \& Грановский, Ю. В. (1971). Планирование эксперимента при поиске оптимальных условий. М.: Наука.

Андреева, Е. В. (2007). Анализ движения зернового материала на вибрационно качающейся ре- 
шетной поверхности сепаратора. Инженернотехническое обеспечение АПК, 3, 700-703.

Арсеньев, В. А., Блехман, И. И., Блехман, Л. И., Васильков, В. Б.,. Феоктистов, А. Ю, \& Якимова, К. С. (2010). Классификация сыпучего материала в условиях вибрационной сегрегации - устройство, моделирование, эксперимент. Обогащение руд, 5, 13-16.

Блехман, И. И., Джанелидзе, Г. Ю. (1964). Вибрациионое перемещение. М.: Наука.

Бочковский, В. М. (1940). Прецизионный аппарат для гравитационной концентрации. Заводская лаборатория, 9(11-12), 1210-1212.

Бочковский, В. М. (1954). Расслаивание как наиболее важный раздел теории и практики гравитации. Горный журнал, 1, 47-55.

Буклагина, Г. В. (2005). Очистка семян трав решетными устройствами. Инженерно-техническое обеспечение АПК, 3, 647-650.

Васильев, А. М., Мачихин, С. А., Стрелюхина, А. Н., \& Рындин, А. А. (2018). Повышение эффективности процессов сепарирования зерновых смесей на рифленой поверхности. Хранение и neреработка сельхозсырья, 3, 98-105. https://doi. org/10.36107/spfp.2018.3

Васильев, А. М., Мачихин, С. А., Стрелюхина, А. Н., \& Рындин, А. А. (2018). Влияние геометрии рифлей опорной поверхности рабочих органов на самосортирование зерновых смесей. Вестник ВГУИТ, 80(3), 26-31. https://doi. org/10.20914/2310-1202-2018-3-26-30

Васильев, А. М., Рындин, А. А., Стрелюхина, А. Н., \& Мачихин, С. А. (2018). Эффект самосортирования в переработке сыпучих пищевых продуктов при вибрационном воздействии. В Материалы 29 симпозиума по реологии (с. 63-64). М.: Институт нефтехимического синтеза им. А.В. Топчиева PAH.

Волков, А. С., Васильев, А. М., \& Киракосян, Д. В. (2009). К вопросу о теоретическом исследовании вибрационного перемещения частиц нижнего слоя зернового потока по рифленой опорной поверхности. В Сборник материалов общеуниверситетской научной конференции молодых ученых и специалистов (с. 218-225). М.: Издательский комплекс МГУПП.
Гортинский, В. В., Демский, А. Б., \& Борискин, М. А. (1980). Процессы сепарирования на зерноперерабатывающих предприятиях. М.: Колос.

Ермольев, Ю. И., \& Кочкин, М. Ю. (2007). Моделирование процесса функционирования зерноочистительного агрегата. Вестник ДГТУ, 7(4), 407-417.

Мачихин, С. А., Рындин, А. А., Васильев, А. М., \& Стрелюхина, А. Н. (2018). Движение верхнего слоя зерновой смеси на вибрирующей рифленой поверхности. Вестник ВГУИТ, 80(4), 55-62. https://doi.org/10.20914/23101202-2018-4-55-62

Мачихин, С. А., Рындин, А. А., Васильев, А. М., \& Стрелюхина, А. Н. (2019). Движение нижнего слоя зерновой смеси на вибрирующей рифленой поверхности. Хранение и переработка сельхозсырья, 2, 115-121. https://doi.org/10.36107/ spfp. 2019.158

Оспанов, А. Б., \& Овчинников, Д. Н. (2002). Вибросепарирование зерновых смесей самосортированием. В Аграрная наука: Проблемы и перспективы (с. 431-434). Курган.

Пашинова, Н. В. (2013). Совершенствование процесса сепарации в вертикальных пневмоканалах (Диссертация кандидата технических наук). Улан-Удэ: ФГБОУ ВПО ВСГУТУ.

Пелевин, А. Е. (2011). Динамика движения твердых сред при гидравлическом вибрационном грохочении. Известия высших учебных заведений. Горный журнал, 4, 127-136.

Птушкина, Г. Е. (1963). Исследование процесса очистки зерна от трудноотделимых минеральных примесей (Диссертация кандидата технических наук). М.

Русанов, А. И. (1957). Сортирование зерна по удельному весу сухим способом (метод меченой частицы). Вестник сельскохозяйственной науки, 1, 110.

Федоренко, И. Я. (2016). Вибрационные процессы и устройства в АПК: Монография. Барнаул: РИО Алтайского ГАУ.

Фоминых, А. В., Пономарева, О. А., Ездин, Д. П. (2012). Истечение сыпучего материала через отверстие в стенке трубы под воздействием вибрации. Вестник Курганской ГСХА, 1, 59-62. 


\title{
Assessment of the Adequacy of the Kinematic Dependences of the Grain Layer in the Vibratory Feeder
}

\author{
Aleksander A. Ryndin \\ Moscow State University of Food Production \\ 11, Volokolamskoe highway, Moscow, 125080, Russian Federation \\ E-mail: aleksandr-ryndin@rambler.ru
}

\section{Alla N. Strelyukhina}

Moscow State University of Food Production 11, Volokolamskoe highway, Moscow, 125080, Russian Federation

E-mail:alstrel@rambler.ru

Sergey A. Machikhin

Moscow State University of Food Production 11, Volokolamskoe highway, Moscow, 125080, Russian Federation E-mail: smachexpert@rambler.ru

Yuliya A. Sorokina State budgetary general education institution of the city of Moscow "School No. 1935" 18, Aircraft designer Mil str., 18, bldg. 2, Moscow, 109431, Russian Federation E-mail: sorokina9101994@yandex.ru

\begin{abstract}
The article is devoted to the practical part of the study of the layer-by-layer movement of the grain flow along the working body of the vibration separator - the feed chute, made in the form of an inclined surface with riffles of variable height, along the line of the greatest slope. The working body is informed of translational harmonic vibrations directed perpendicular to the installed riffles. The results of checking the adequacy and trajectory of the grain layer, calculated using the mathematical, proposed by the authors, and experimental values are presented. The results of the study of the influence of the oscillation frequency of the working body on the trajectory and speed of movement of particles of the upper and lower layers of the grain mixture are presented.
\end{abstract}

Keywords: separators, auto-separation, base surface, riffles, vibration frequency, vibration amplitude

\section{References}

Abiduev, A. A. (2010). Sovershenstvovanie protsessa ochistki semennogo zerna [Improving the process of cleaning seed grain]. Ulan-Ude: Izd-vo FGOU VPO BGSKhA im. V. R. Filippova.

Abiduev, A. A., \& Abiduev A. A. (2011). Obosnovanie tekhnologii ochistki semyan pshenitsy [Rationale for the technology of cleaning wheat seeds]. Vestnik VSGTU [Bulletin of the East Siberian State University of Technology and Management], 4, 86-90.

Adler, Yu. P., Markova, E. V., \& Granovskii, Yu. V. (1971). Planirovanie eksperimenta pri poiske optimal'nykh uslovii [Planning an experiment to find optimal conditions]. Moscow: Nauka.
Andreeva, E. V. (2007). Analiz dvizheniya zernovogo materiala na vibratsionno kachayushcheisya reshetnoi poverkhnosti separatora [Analysis of the movement of grain material on the vibration-swinging sieve surface of the separator]. Inzhenerno-tekhnicheskoe obespechenie APK [Engineering and technical support of the agro-industrial complex], 3, 700-703.

Arsen'ev, V. A., Blekhman, I. I., Blekhman, L. I., Vasil'kov, V. B.,. Feoktistov, A. Yu, \& Yakimova, K. S. (2010). Klassifikatsiya sypuchego materiala V usloviyakh vibratsionnoi segregatsii - ustroistvo, modelirovanie, eksperiment [Classification of bulk material in conditions of vibration segregation device, simulation, experiment]. Obogashchenie rud [Beneficiation of ores], 5, 13-16. 
Blekhman, I. I., Dzhanelidze, G. Yu. (1964). Vibratsionnoe peremeshchenie [Vibration displacement]. Moscow: Nauka.

Bochkovskii, V. M. (1940). Pretsizionnyi apparat dlya gravitatsionnoi kontsentratsii [Precision Gravity Concentration Apparatus]. Zavodskaya laboratoriya [Factory laboratory], 9(11-12), 1210-1212.

Bochkovskii, V. M. (1954). Rasslaivanie kak naibolee vazhnyi razdel teorii i praktiki gravitatsii [Delamination as the most important section of the theory and practice of gravity]. Gornyi zhurnal [Mining magazine], 1, 47-55.

Buklagina, G. V. (2005). Ochistka semyan trav reshetnymi ustroistvami [Cleaning grass seeds with sieve devices]. Inzhenerno-tekhnicheskoe obespechenie APK [Engineering and technical support of the agro-industrial complex], 3, 647-650.

Ermol'ev, Yu. I., \& Kochkin, M. Yu. (2007). Modelirovanie protsessa funktsionirovaniya zernoochistitel'nogo agregata [Modeling the process of functioning of the grain cleaning unit]. Vestnik DGTU [Bulletin of the Dagestan State Technical University], 7(4), 407-417.

Fedorenko, I. Ya. (2016). Vibratsionnye protsessy $i$ ustroistva $v$ APK: Monografiya [Vibration processes and devices in the agro-industrial complex: Monograph]. Barnaul: RIO Altaiskogo GAU.

Fominykh, A. V., Ponomareva, O. A., Ezdin, D. P. (2012). Istechenie sypuchego materiala cherez otverstie $\mathrm{v}$ stenke truby pod vozdeistviem vibratsii [The outflow of bulk material through a hole in the pipe wall under the influence of vibration]. Vestnik Kurganskoi GSKhA [Bulletin of the Kurgan State Agricultural Academy. T. S. Maltseva], 1, 59-62.

Gortinskii, V. V., Demskii, A. B., \& Boriskin, M. A. (1980). Protsessy separirovaniya na zernopererabatyvayushchikh predpriyatiyakh [Separation processes in grain processing plants]. Moscow: Kolos.

Machikhin, S. A., Ryndin, A. A., Vasil'ev, A. M., \& Strelyukhina, A. N. (2018). Dvizhenie verkhnego sloya zernovoi smesi na vibriruyushchei riflenoi poverkhnosti [The movement of the top layer of the grain mixture on a vibrating corrugated surface]. Vestnik VGUIT [Voronezh State University of Engineering Technologies Bulletin], 80(4), 55-62. https://doi.org/10.20914/2310-1202-2018-4-55-62

Machikhin, S. A., Ryndin, A. A., Vasil'ev, A. M., \& Strelyukhina, A. N. (2019). Dvizhenie nizhnego sloya zernovoi smesi na vibriruyushchei riflenoi poverkhnosti [The movement of the bottom layer of the grain mixture on a vibrating corrugated surface]. Khranenie i pererabotka sel'khozsyr'ya [Storage and Processing of Farm Products], 2, 115121. https://doi.org/10.36107/spfp.2019.158

Ospanov, A. B., \& Ovchinnikov, D. N. (2002). Vibroseparirovanie zernovykh smesei samosor- tirovaniem [Vibration separation of grain mixtures by self-sorting]. In Agrarnaya nauka: Problemy $i$ perspektivy [Agricultural Science: Problems and Prospects] (pp. 431-434). Kurgan.

Pashinova, N. V. (2013). Sovershenstvovanie protsessa separatsii $v$ vertikal'nykh pnevmokanalakh (Dissertatsiya kandidata tekhnicheskikh nauk) [Improvement of the separation process in vertical pneumatic channels (Doctoral dissertation)]. UlanUde: FGBOU VPO VSGUTU.

Pelevin, A. E. (2011). Dinamika dvizheniya tverdykh sred pri gidravlicheskom vibratsionnom grokhochenii [Dynamics of movement of solids with hydraulic vibrating screening]. Izvestiya vysshikh uchebnykh zavedenii. Gornyi zhurnal [University news. Mining magazine], 4, 127-136.

Ptushkina, G. E. (1963). Issledovanie protsessa ochistki zerna ot trudnootdelimykh mineral'nykh primesei (Dissertatsiya kandidata tekhnicheskikh nauk) [Investigation of the process of cleaning grain from hard-to-separate mineral impurities (Master's thesis)]. Moscow.

Rusanov, A. I. (1957). Sortirovanie zerna po udel'nomu vesu sukhim sposobom (metod mechenoi chastitsy) [Dry sorting of grain by specific gravity (tagged particle method)]. Vestnik sel'skokhozyaistvennoi nauki [Agricultural Science Bulletin], 1, 110.

Vasil'ev, A. M., Machikhin, S. A., Strelyukhina, A. N., \& Ryndin, A. A. (2018). Povyshenie effektivnosti protsessov separirovaniya zernovykh smesei na riflenoi poverkhnosti [Improving the efficiency of separation processes of grain mixtures on a corrugated surface]. Khranenie i pererabotka sel'khozsyr'ya [Storage and Processing of Farm Products], 3, 98-105. https://doi.org/10.36107/spfp.2018.3

Vasil'ev, A. M., Machikhin, S. A., Strelyukhina, A. N., \& Ryndin, A. A. (2018). Vliyanie geometrii riflei opornoi poverkhnosti rabochikh organov na samosortirovanie zernovykh smesei [Influence of the geometry of the groove of the support surface of the working bodies on the self-sorting of grain mixture]. Vestnik VGUIT [Voronezh State University of Engineering Technologies Bulletin], 80(3), 26-31. https://doi.org/10.20914/2310-1202-2018-3-26-30 Vasil'ev, A. M., Ryndin, A. A., Strelyukhina, A. N., \& Machikhin, S. A. (2018). Effekt samosortirovaniya $\mathrm{v}$ pererabotke sypuchikh pishchevykh produktov pri vibratsionnom vozdeistvii [Self-sorting effect in the processing of bulk food products under vibration exposure]. In Materialy 29 simpoziuma po reologii [Proceedings of the 29th Symposium on Rheology] (pp. 63-64). Moscow: Institut neftekhimicheskogo sinteza im. A.V. Topchieva RAN.

Volkov, A. S., Vasil'ev, A. M., \& Kirakosyan, D. V. (2009). K voprosu o teoreticheskom issledovanii vibratsionnogo peremeshcheniya chastits nizh- 
nego sloya zernovogo potoka po riflenoi opornoi poverkhnosti [On the theoretical study of the vibrational movement of particles in the lower layer of the grain flow along a corrugated support surface]. In Sbornik materialov obshcheuniversitetskoi nauchnoi konferentsii molodykh uchenykh $i$ spetsialistov [Collection of materials of the university-wide scientific conference of young scientists and specialists] (pp. 218-225). Moscow: Izdatel'skii kompleks MGUPP. 